\title{
Role of carboprost in prevention of postpartum hemorrhage
}

\author{
Akanksha Lamba*, Godawari Joshi, Madhulika Gupta \\ Department of Obstetrics and Gynaecology, Dr. Sushila Tiwari Memorial Hospital, Haldwani, Uttarakhand, India
}

Received: 23 June 2016

Accepted: 28 June 2016

*Correspondence:

Dr. Akanksha Lamba,

E-mail: dr.akanksha2709@gmail.com

Copyright: ( $\odot$ the author(s), publisher and licensee Medip Academy. This is an open-access article distributed under the terms of the Creative Commons Attribution Non-Commercial License, which permits unrestricted non-commercial use, distribution, and reproduction in any medium, provided the original work is properly cited.

\section{ABSTRACT}

Background: Postpartum hemorrhage (PPH) is one of the most common causes of maternal death throughout the world. Pregnancy and childbirth involves significant health risks, even to women with no preexisting health problem. The objective of this study was to analyze the role of carboprost in prevention of PPH.

Methods: This prospective observational study was conducted in the department of obstetrics and gynaecology of Dr. Sushila Tiwari Memorial Hospital, Haldwani, Uttarakhand, India. A total number of 100 cases delivering in the labour room that fulfilled the selection criteria were included. Carboprost 250 microgram $(1 \mathrm{ml})$ was administered intramuscularly to each of the case just after the delivery of the anterior shoulder of baby. Duration of third stage, amount of blood loss, incidence of PPH and side effect profile was studied.

Results: Carboprost reduces the duration and amount of blood loss in the third stage of labour but is associated with a number of unpleasant side effects.

Conclusions: Active management of third stage of labour is recommended in all cases. Carboprost is highly efficacious in reducing the incidence of PPH.

Keywords: Carboprost, PPH, BRASSE-V-Drape

\section{INTRODUCTION}

Postpartum haemorrhage is one of the leading causes of maternal morbidity and mortality. Every day about 1500 women die from pregnancy or child birth related complications. ${ }^{1}$ In India it is about $25 \%$ of the maternal mortality. Various drugs and surgical techniques are available for prevention and management of pph. Preventing PPH is also important due to a limited access to emergency medical facilities.

Uterotonics administration with the delivery of the anterior shoulder, early cord clamping and fundal massage are implemented in Active management of the third stage of labour. ${ }^{2}$ Active management of third stage of labour decreases the incidence of PPH as compared to the expectant management. ${ }^{3}$

Postpartum haemorrhage is defined as blood loss of more than $500 \mathrm{ml}$ after delivery. Uterotonics used for prophylaxis against PPH includes oxytocin, methylergometrine and 15 (S) 15 methyl PGF2 $\alpha$. Studies have shown that there are wide variations in the management of third stage of labour. Uterotonic therapy has shown to reduce the incidence of PPH by $40 \%$. But it is associated with side effects like nausea, vomiting, hypertension, shivering diarrhoea, myocardial infarction, cardiac arrest and pulmonary oedema etc. Carboprost tromethamine is a PGF2 $\alpha$ analogue which is administered intramuscularly.

The present study is an attempt to evaluate the role of carboprost tromethamine in the active management of third stage. Efficacy of carboprost in preventing and control-ling pp. needs to be studied extensively.

\section{METHODS}

This prospective observational study was conducted in the department of obstetrics and gynaecology of Dr. Sushila Tiwari Memorial Hospital, Haldwani, 
Uttarakhand, India. A total number of 100 cases delivering in the labour room of Dr. Sushila Tiwari Memorial Government Hospital Haldwani, Uttarakhand, India who fulfilled the selection criteria were included in the study.

\section{Inclusion criteria}

Full term singleton pregnancy with spontaneous vaginal delivery.

\section{Exclusion criteria}

- Hemoglobin less than $7 \mathrm{~g} / \mathrm{dl}$

- History of postpartum hemorrhage in previous pregnancies

- Pregnancy induced hypertension

- Malpresentation

- Coagulation abnormalities

- Patients undergoing operative vaginal delivery

- Antepartum hemorrhage

- Intra uterine demise

- Patients who were known cases of medical disorders like

- Diabetes

- Heart disease

- Stroke

- Peripheral vascular disorders

- Epilepsy

- Asthma

- Liver, kidney and adrenal gland disorders

- History of previous caesarian section

- Cases with induction of labour with oxytocin

An informed written consent was obtained from each patient who satisfied the inclusion criteria. A thorough general and systemic examination of all the cases was done including cardiovascular system, respiratory system, per abdomen and per vaginal examinations. All relevant investigations including a pre labour evaluation of the hemoglobin and hematocrit were done. Carboprost 250 microgram $(1 \mathrm{ml})$ was administered intramuscularly to each of the case just after the delivery of the anterior shoulder of baby.

The placenta was delivered by controlled cord traction; placenta and membranes were examined for completeness after expulsion. The blood loss during the third stage of labour was measured in blood collecting bag (BRASSS-V-DRAPE). Blood clots were weighed separately considering $1 \mathrm{gm}$ equal to $1 \mathrm{ml}$ of blood 86 . Blood soaked swabs were weighed, the known dry weight subtracted and the calculated volume added to that of the blood volume of measuring bag.

Postpartum hemorrhage in the present study was considered as blood loss of more than $500 \mathrm{ml}$ during the third stage of labour. The amounts of blood loss, duration of the third stage of labour (interval between administration of prostodin and expulsion of placenta) third stage complications like retained placenta were noted. The maternal hemoglobin and hematocrit were repeated 24 to 48 hours after the delivery and the change in haemoglobin and hematocrit were taken as an objective measure of postpartum hemorrhage. Blood pressure was recorded before onset of labour and thirty minutes after delivery. Patients were observed for two hours following delivery for vital signs and bleeding per vagina. The occurrences of side effects like nausea, vomiting, shivering, fever, diarrhoea etc. within the first two hours of delivery were recorded.

\section{RESULTS}

Table 1: Sociodemographic profile.

\begin{tabular}{|ll|}
\hline Characteristics & \\
\hline Age in years & Number of patients \\
\hline $18-23$ & 40 \\
\hline $24-28$ & 45 \\
\hline $29-33$ & 14 \\
\hline $34-38$ & 01 \\
\hline Parity & \\
\hline Primi & 59 \\
\hline Multi & 41 \\
\hline
\end{tabular}

The age group ranged between 18-38 years. Majority of the patients be-longed to age group 24-28 years.

Table 2: Distribution of patients according to duration of third stage of labour.

\begin{tabular}{|l|l|}
\hline Time (minutes) & Number of patients \\
\hline$<5$ minutes & 59 \\
\hline 5 to 10 minutes & 35 \\
\hline$>10$ to 15 minutes & 6 \\
\hline$>15$ minutes & 0 \\
\hline
\end{tabular}

The above table shows that in maximum number of patients third stage of labour lasted for less than 5 minutes. Mean duration of third stage of labour was $5.03 \pm 1.9$.

Table 3: Distribution of patients according to amount of blood loss during third stage of labour.

\begin{tabular}{|l|l|}
\hline Amount of blood loss $(\mathrm{ml})$ & Number of patients \\
\hline Up to 100 & 34 \\
\hline $101-200$ & 53 \\
\hline $201-300$ & 11 \\
\hline $301-400$ & 2 \\
\hline $401-500$ & 0 \\
\hline More than $500 \mathrm{ml}$ & 0 \\
\hline
\end{tabular}

The maximum number of patients had blood loss between 100-200 ml. Mean amounts of blood loss during third stage of labour in 127. $60 \pm 54.14$. 
Table 4: Pre and post-delivery hemoglobin and haematocrit levels.

\begin{tabular}{|lll|}
\hline & Pre-delivery Hob & Post-delivery Hb \\
\hline Mean \pm SD & $10.2 \pm 1.6$ & $9.63 \pm 1.6$ \\
\hline & Pre-delivery Hct & Post-delivery Hct \\
\hline Mean \pm SD & $30.72 \pm 4.8$ & $28.8 \pm 4.9$ \\
\hline
\end{tabular}

The difference between pre-delivery and post-delivery hemoglobin was $0.72 \mathrm{gm} / \mathrm{dl} \pm 0.31$ and haematocrit was 2.31 \pm 0.99 . Fall in $\mathrm{Hb}$ and Hct was not significant.

Table 5: Side effect profile.

\begin{tabular}{|l|l|}
\hline Side effects & Number of patients \\
\hline Nausea & 9 \\
\hline Vomiting & 11 \\
\hline Diarrhea & 16 \\
\hline Raised Dbp & 0 \\
\hline Headache & 0 \\
\hline Shivering & 0 \\
\hline Fever & 4 \\
\hline
\end{tabular}

This patient experienced side effects like nausea (9\%), vomiting (11\%) and diarrhoea (16\%) and fever (4\%).

\section{DISCUSSION}

The primary aim in the management of postpartum hemorrhage should be its prevention. The active management of the third stage with routine prophylactic ad-ministration of oxytocics at the time of delivery of the anterior shoulder of the fetus has been shown to reduce the risk of postpartum hemorrhage by about $40 \%{ }^{4}$

PGF $2 \alpha$ is a powerful uterotonics agent with a physiological role in human parturition both in the delivery of the foetus and control of post-partum bleeding. A more potent analogue 15 (S)-15 methyl PGF $2 \alpha$ (carboprost tromethamine) is available and has been in use for more than three decades. When compared to natural PGF2 $\alpha$, this is more potent and long acting. Thus prostaglandins are the group of uterine stimulating agents used in the management of third stage of labour and in the prevention of postpartum hemorrhage with minimal side effects.

In the present study, the mean maternal age (years) is $24.36 \pm 3.2$.

All the three groups were homogenous with regard to age of the patients. In a study conducted by Singh $\mathrm{N}$ et al the mean maternal age (years) was 25 years in carboprost group..$^{5}$

In our study the distribution of parity shows that majority of the women are primigravida. The mean parity was $1.68 \pm 1.08$. Bhide $\mathrm{P}$ et al studied the comparison of oxytocin, methylergometrine and carboprost in third stage of labour and found that in oxytocin group 50\% patients were primigravida, in methergin group $40 \%$ were primigravida and in carboprost group $60 \%$ were primigravida. $^{6}$

In the present study mean duration of third stage of labour was $5.03 \pm 1.9$ minutes in carboprost group. Our results are in accordance with the study of Yuen PH et al and Chua $\mathrm{S}$ et al. ${ }^{7,8}$

Bhide $\mathrm{P}$ et al studied the use of oxytocin, methylergometrine and carboprost during third stage of labour and found that the duration of $3^{\text {rd }}$ stage was 6 minutes 30 seconds, 5 minutes and 3 minutes 15 seconds respectively. ${ }^{6}$ The results of our study do not match with those of the following studies. Reddy et al in did a comparative study of different uterotonics in high risk patients for atonic postpartum hemorrhage and found the mean duration of third stage of labour was 2.44 minutes in methyl ergometrine group and 2.33 minutes in carboprost group. ${ }^{9}$ Bhattacharya et al did a similar study on effect of uterotonics in active management of third stage of labour and found the mean duration of third stage of labour was 8.06 minutes in methyl ergometrine group and 4.8 minutes in carboprost group. ${ }^{10}$ In a study by Anjaneyulu et al the mean duration of third stage of labour in methyl ergometrine group was 6.1 minutes and in carboprost group was 3.5 minutes. ${ }^{11}$ In another study by Purushotham BJ et al it was 3.6 minutes and 2.63 minutes for methyl ergometrine and carboprost tromethamine groups respectively. ${ }^{12}$

In the present study mean blood loss in the third stage was $127.6 \pm 54.14$. In a study conducted by Anjaneyulu et al mean blood loss in methyl ergometrine group was $154.9 \pm 105.6 \mathrm{ml}$ while that in carboprost group was $95.2 \pm 89.0 \mathrm{ml}$. Reddy et al observed a mean blood loss of $202 \pm 84 \mathrm{ml}$ in methyl ergometrine group and $127 \pm 97 \mathrm{ml}$ in carboprost group. Thus a lot of diligence should be applied while dealing with multiparas and those at high risk of developing postpartum hemorrhage.

In the present study there was a reduction of post part haemoglobin; difference was $0.72 \pm 0.31 \mathrm{gm} / \mathrm{dl}$. The difference was found to be statistically insignificant. It was analyzed that the fall in hemoglobin was considerably minimized with the use of active management of third stage of labour irrespective of the uterotonics used and its mode of administration. Patients experienced side effects like nausea (9\%), vomiting $(11 \%)$ diarrhoea $(16 \%)$ and fever $(4 \%)$.

In the study done by Singh $\mathrm{N}$ et al side effects were seen in $2(3 \%)$ methylergometrine group (vomiting-1, diarrhea-1) and in $8(12.4 \%)$ in carboprost group (nausea2 , vomiting- 3 , diarrhea 3 ). Chua $\mathrm{S}$ et al reported from their study that the disadvantages of caboprost were higher cost and statistically significant increase in the incidence of profuse and frequent diarrhoea. 
Lamont et al studied the efficacy and safety of an analogue of 15 methyl prostaglandin (PGF2 alpha) and it was compared with syntometrine for the active management of third stage of labour and in prevention of postpartum haemorrhage. ${ }^{13}$ They reported that diarrhoea was significantly more in PGF $2 \alpha$ group.

\section{CONCLUSION}

It is concluded from this study that carboprost is effective in the active management of the third stage of labour in low risk cases. Carboprost reduces the duration of third stage, amount of blood loss, incidence of pph, fall in hemoglobin and haematocrit percentage and need for additional oxytocics. But carboprost was found to cause nausea, vomiting and diarrhoea and is expensive than other uterotonics. Active management of third stage of labour is recommended in all cases.

Funding: No funding sources Conflict of interest: None declared

Ethical approval: The study was approved by the Institutional Ethics Committee

\section{REFERENCES}

1. Maternal Mortality. Available at URL: www.who.int. Accessed on 01 June, 2016.

2. Cunningham FG, Gant NF, Leveno KJ (eds). Obstetrical haemorrhage. Williams Obstetrics $23^{\text {rd }}$ edn. USA, McGraw Hill. 2009:757-803.

3. Hofmeyr GJ, Gulmezoglu AM. New development in the management of postpartum hemorrhage. In: Bonner J. Re-cent Advances in Obstetrics and Gynaecology. $21^{\text {st }}$ edn. London. Churchill Livingstone. 2000:56-66.

4. Katzung BG. The ergot alkaloids. Basic and clinical pharmacology, Katzung, $6^{\text {th }}$ Edn. USA, Aplleton and Hange; 1995:251-275.
5. Singh N, Singh U. Methylergometrine and carboprost tromethamine prophy-laxis for postpartum haemorrhage. J Obstet Gynecol India. 2005;55(4):325-8.

6. Bhide P, Bhide S, Daftary S. Management of third stage of labour. J Obstet Gyne-aecol Ind. 1994;43:734-7.

7. Yuen PH, Chan NST, Yim SF, Chang AMZ. A randomized double blind comparison of syntometrine and syntocinon in the management of the third, stage of labour. Br J Obstet Gynaecol. 1995;102:377-80.

8. Chua S, Chew SL, Yeoh CL, Roy AC, Ho LM, Selamat N, et al. A randomized controlled study of prostaglandin 15-methyl F2 alpha compared with syntometrine for prophylactic use in the third stage of labour. Aust N Z J Obstet Gynaecol. 1995;35(4):413-6.

9. Reddy R, Shenoy JS. Active management of third stage of labour: a comparative study in high risk patients for atonic PPH. J Obstet Gynecol India. 2001;51:44-7.

10. Bhattacharya P, Devi PK, Jain S. Prophylactic use of 15 (S) 15 methyl PGE2 $\alpha$ by intramuscular route for control of postpartum bleeding: a comparative trial with methylergometrine. Acta Obstet Gynecol Scand Suppl. 1988;145:13-5.

11. Anjaneyulu R, Devi PK, Jain S. Prophylactic use of 15 (5) methyl PGF $2 \alpha$ by IM route: a controlled clinical trial. Acta Obstet Gynecol Scand Suppl. 1988;145:9-11.

12. Purushottam J, Roopa P. Prophylactic intramuscular PGF $2 \alpha$ versus intra-venous methyl ergometrine for prevention of atonic PPH in high risk women. J Obstet Gynecol India. 2008;58(5):417-20.

13. Lamont RF, Morgan DJ, Logue M, Gordon H. A prospective randomised trial to compare the efficacy and safety of hemabate and syntometrine for the prevention of primary postpartum haemorrhage. Prostaglandins Other Lipid Mediat. 2001;66(3):20310.

Cite this article as: Lamba A, Joshi G, Gupta M. Role of carboprost in prevention of postpartum hemorrhage. Int J Reprod Contracept Obstet Gynecol 2016;5:2151-4. 